\title{
Open repair of a new aneurysm of the thoracoabdominal aorta after endovascular stent placement
}

Siyamek Neragi-Miandoab, MD, James Tuchak, MD, Mamdouh Bakhos, MD, and Jeffrey Paul Schwartz, MD, Maywood, III

W e describe the case of a 63-year-old woman with aneurysm of the descending aorta who initially underwent intravascular stent grafting of the descending thoracic aorta followed by coil embolization, as well as additional cuff placement at the very proximal portion of the stent, to treat a pseudoaneurysm at the proximal stent margin. The stent graft was covering the subclavian artery, and therefore her left radial artery pulse was weakened, although it remained patent because of retrograde back flow. Figure 1 shows the proximal end of the stent covering the left subclavian artery and partially covering the left carotid artery. The patient returned to the hospital with severe left-sided chest and back pain. Radiographic studies demon-

From the Department of Thoracic and Cardiovascular Surgery, Loyola University Chicago, Stritch School of Medicine, Maywood, Ill.

Received for publication Feb 15, 2006; accepted for publication Feb 22, 2006.

Address for reprints: Siyamek Neragi-Miandoab, MD, Loyola University Chicago, Stritch School of Medicine, Department of Thoracic and Cardiovascular Surgery, 2160 South First Ave, Building 110, Room 6243, Maywood, IL 60153 (E-mail: Sneragi@yahoo.com).

J Thorac Cardiovasc Surg 2006;132:157-8

$0022-5223 / \$ 32.00$

Copyright (C) 2006 by The American Association for Thoracic Surgery doi:10.1016/j.jtcvs.2006.02.043 strated an aneurysm surrounding the distal limb of the stent graft with thrombus extending around the stent into the aneurysmal sac, with a short distance between the aneurysm and celiac artery that was inadequate for landing an additional stent between the previous thoracic stent and the celiac trunk. Therefore the patient underwent open repair.

A left posterolateral thoracotomy was made at the level of the eighth intercostal space. The incision was extended into the abdomen, the abdominal fascia was dissected out, and the diaphragm was taken down radially with an endo-GIA stapler (US Surgical, Tyco Healthcare, Norwalk, CT) approximately $3 \mathrm{~cm}$ from the chest wall. Cardiopulmonary bypass was initiated through the left femoral vessels. A crossclamp was applied on the distal aorta, followed by clamping of the aneurysm with the stent graft within. The aorta was opened, and after the back bleeding from the celiac artery was noted, this was clamped individually. A 26-mm graft was then anastomosed in an endto-end fashion to the distal aorta just above the celiac trunk. A clamp was placed on the graft, and the distal aortic clamp was released to resume perfusion to the celiac artery. After $1 \mathrm{~cm}$ of distal stent was resected, the proximal anastomosis was then performed in an end-to-end fashion from the graft to the endograft, with the patient's native aortic wall incorporated into the suture line peripheral to the endograft. Figure 2 illustrates the operative steps. There were no perioperative or postoperative complications, and the patient was discharged home on postoperative day 7 .

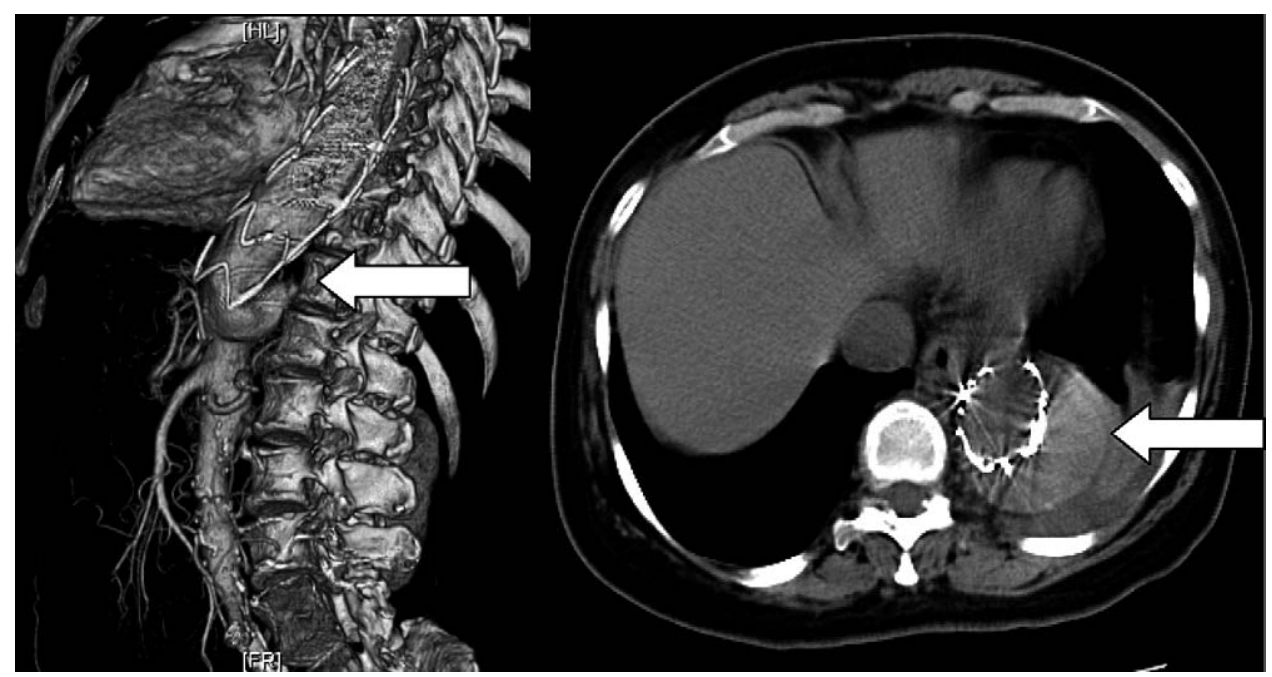

Figure 1. Computed tomographic scan reconstruction demonstrating the relationship between the aneurysm, stent, and celiac artery. 


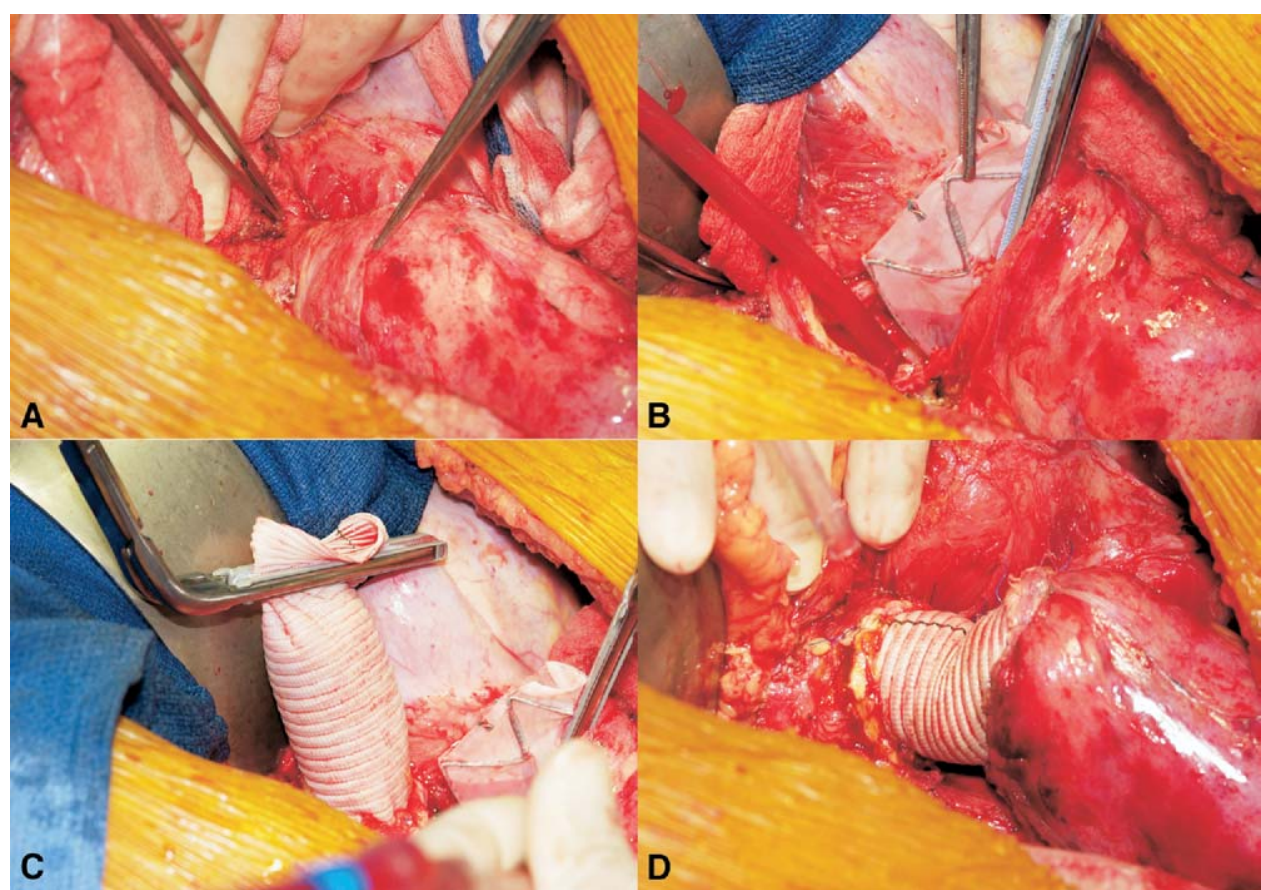

Figure 2. A, Aneurysmal dilation of the aorta: short neck between the aneurysm and the celiac artery. B, Dacron graft anastomosis: the celiac artery was preserved. C, Distal anastomosis. D, Complete anastomosis.

\section{Discussion}

Endoleak is relatively common and the most disappointing complication of stent graft treatment of aortic aneurysm. ${ }^{1-3}$ Even in the absence of an endoleak, the aneurysm might continue to enlarge. The pathogenesis of this phenomenon remains unclear, ${ }^{4}$ and therefore surveillance after endovascular stent placement must include regular evaluation of aneurysm size or aneurysm volume. Aneurysm sac enlargement without an endoleak is not a benign condition. ${ }^{4}$ Sakai and colleagues ${ }^{5}$ reported that the caliber of the aneurysm continued to increase compared with its diameter at computed tomography immediately after stent graft placement in $30 \%$ of patients without evidence of perigraft leak. Recurrent or persistent pressurization of the aneursymal sac will eventually result in rupture. Furthermore, continued expansion of the aneurysmal sac can result in dilatation of the aorta and threaten the integrity of the proximal and distal anastomotic seals. ${ }^{4}$ An enlargement of the aneurysm after treatment indicates a failure of the procedure. ${ }^{1}$ In case of endotension and a growing aneurysm, an open operation and placement of a regular vascular graft should be considered. ${ }^{4}$

\section{Conclusion}

A continuous aneurysmal dilation of the aorta after endovascular stent placement should be managed with open repair if an endovascular approach is not feasible.

\section{References}

1. Rozenblit A, Marin ML, Veith FJ, Cynamon J, Wahl SI, Bakal CW. Endovascular repair of abdominal aortic aneurysm: value of postoperative follow-up with helical CT. AJR Am J Roentgenol. 1995;165:1473-9.

2. Blum U, Langer M, Spillner G, et al. Abdominal aortic aneurysms: preliminary technical and clinical results with transfemoral placement of endovascular self-expanding stent-grafts. Radiology. 1996;198:25-31.

3. Chuter TA, Risberg B, Hopkinson BR, et al. Clinical experience with a bifurcated endovascular graft for abdominal aortic aneurysm repair. $J$ Vasc Surg. 1996;24:655-66.

4. van Sambeek MR, Hendriks JM, Tseng L, van Dijk LC, van Urk H. Sac enlargement without endoleak: when and how to convert and technical considerations. Semin Vasc Surg. 2004;17:284-7.

5. Sakai T, Dake MD, Semba CP, et al. Descending thoracic aortic aneurysm: thoracic CT findings after endovascular stent-graft placement. Radiology. 1999;212:169-74. 